\title{
Human-Mediated Dispersal of Seeds by the Airflow of Vehicles
}

\author{
Moritz von der Lippe ${ }^{1,2 *}$, James M. Bullock' ${ }^{1}$ Ingo Kowarik ${ }^{2}$, Tatjana Knopp ${ }^{1,3}$, Matthias Wichmann ${ }^{1,4}$ \\ 1 Centre for Ecology and Hydrology, Wallingford, United Kingdom, 2 Department of Ecology, Technische Universität Berlin, Berlin, Germany, 3 Department of Animal
} Ecology, Universität Potsdam, Potsdam, Germany, 4 Biodiversity and Systematic Botany, Universität Potsdam, Potsdam, Germany

\begin{abstract}
Human-mediated dispersal is known as an important driver of long-distance dispersal for plants but underlying mechanisms have rarely been assessed. Road corridors function as routes of secondary dispersal for many plant species but the extent to which vehicles support this process remains unclear. In this paper we quantify dispersal distances and seed deposition of plant species moved over the ground by the slipstream of passing cars. We exposed marked seeds of four species on a section of road and drove a car along the road at a speed of $48 \mathrm{~km} / \mathrm{h}$. By tracking seeds we quantified movement parallel as well as lateral to the road, resulting dispersal kernels, and the effect of repeated vehicle passes. Median distances travelled by seeds along the road were about eight meters for species with wind dispersal morphologies and one meter for species without such adaptations. Airflow created by the car lifted seeds and resulted in longitudinal dispersal. Single seeds reached our maximum measuring distance of $45 \mathrm{~m}$ and for some species exceeded distances under primary dispersal. Mathematical models were fit to dispersal kernels. The incremental effect of passing vehicles on longitudinal dispersal decreased with increasing number of passes as seeds accumulated at road verges. We conclude that dispersal by vehicle airflow facilitates seed movement along roads and accumulation of seeds in roadside habitats. Dispersal by vehicle airflow can aid the spread of plant species and thus has wide implications for roadside ecology, invasion biology and nature conservation.
\end{abstract}

Citation: von der Lippe M, Bullock JM, Kowarik I, Knopp T, Wichmann M (2013) Human-Mediated Dispersal of Seeds by the Airflow of Vehicles. PLoS ONE 8(1): e52733. doi:10.1371/journal.pone.0052733

Editor: Mari Moora, University of Tartu, Estonia

Received September 5, 2012; Accepted November 20, 2012; Published January 8, 2013

Copyright: (c) 2013 von der Lippe et al. This is an open-access article distributed under the terms of the Creative Commons Attribution License, which permits unrestricted use, distribution, and reproduction in any medium, provided the original author and source are credited.

Funding: M. von der Lippe and T. Knopp were funded by research grants of the German Academic Exchange Service (DAAD, http://www.daad.de). M. Wichmann and J. Bullock were funded by the NERC research grant NE/B503141/1. The funders had no role in study design, data collection and analysis, decision to publish, or preparation of the manuscript.

Competing Interests: The authors have declared that no competing interests exist.

* E-mail: moritz.vdlippe@tu-berlin.de

\section{Introduction}

Human-mediated dispersal (HMD) is a driver of long-range spread of plant species and is increasingly gaining attention in dispersal [1] and invasion ecology [2,3]. Roadsides are particularly relevant in terms of HMD as some invasive species expand their ranges rapidly along road networks [4,5]. At the landscape scale, several studies have demonstrated that the density of human transportation corridors [6,7] or human use of roads [8] are related to the frequency or spread rate of non-native plants.

HMD by vehicles has only been studied in a few contexts to date. Several studies have demonstrated potential dispersal through attachment to vehicles by finding seeds of many species in samples of mud from the surface of vehicles [9-13]. Only recently, the spatial reach of dispersal by seeds attaching to motor vehicles has been quantified, showing that long-distance dispersal over more than $256 \mathrm{~km}$ is achieved by a sizeable proportion of seeds that become attached with mud on cars [14]. Second, studies of seed deposition along roadsides have considered the combined roles of attachment and airflow by vehicles for dispersal. To exclude non-traffic-related dispersal, seeds have been collected in long motorway tunnels $[15,16]$ and seeds of known cultivars of oilseed rape/canola have been exposed on the roads and their offspring traced with molecular markers [17]. Gaps remain, however, in our understanding and in the quantifications of the mechanisms of vehicle-related seed transport. For example, to our knowledge, there has been no quantification of the dispersal kernel of seeds transported by cars (but see [14]), including the distribution of dispersal distances. In addition, the role of slipstreams and air turbulence caused by passing vehicles [18] has been suggested to be important in the spread of roadside plant populations [17] but this process has not yet been studied.

Turbulent airflow is reported by studies of the aerodynamics of vehicles [18]. A narrow zone around a passing vehicle is affected by turbulence, caused by flow separation from the boundary layer at the surface of the moving vehicle. Although it has a stochastic nature, the mean direction of this turbulence leads to a characteristic flow field around the moving vehicle. Besides turbulent airflow close to the vehicle, it is primarily the slipstream in the wake of the passing vehicle that affects airflow in the direction of the traffic movement. This slipstream acts over a distance which is determined as a multiple of the vehicle height $[19,20]$. The airflow in this "far wake region" is caused by a velocity deficit in the wake of the moving vehicle and tends to be laminar. Previous studies of seed dispersal by wind [21] suggest that vehicle's airflow could influence the dispersal of seeds along roads.

A better mechanistic understanding through experimental quantification has been achieved for some seed dispersal processes including wind dispersal [21-26] and, to some extent, animal dispersal [27-31]. While wind and also animals often act as vectors for primary dispersal, humans, as in our experiment, normally 
trigger secondary dispersal. For HMD, kernels have recently been quantified experimentally for dispersal on footwear $[1,2]$ and cars [14]. The results indicate that HMD may follow well defined mechanisms and that dispersal distances can far exceed primary dispersal vectors. To expand on earlier results on dispersal by human activity, we aim in this paper to extend experimental quantification of HMD to that by airflow of vehicles.

By quantifying dispersal kernels for four species, we determine the effect of repeated vehicle passes on the parallel and lateral movements of seeds. We hypothesize that: i) repeated vehicle passes result in continued secondary dispersal of seeds along the road; ii) turbulent airflow around passing vehicles causes a lateral movement of seeds towards the road verge; and iii) the extent of seed transport by passing vehicles depends on seed traits, such as morphology. To test these hypotheses we set up an experiment in which a car was repeatedly driven through lines of marked seeds comprising four species. Distance and direction of seed movement was quantified.

\section{Methods}

\section{Ethics Statement}

The study took place on a private parking ground and was permitted by Centre of Ecology and Hydrology at Winfrith Technology Centre, Winfrith, Dorset, UK. No specific permits and approvals were required, as the speed of car driving during the experiment did not exceed the maximum speed allowed in the area. No seeds of protected species were used. Three of our study species commonly occur in the study area but to avoid any risk of establishment of the fourth species, we applied a microwave treatment to the seeds of Ambrosia artemisiifolia to prevent any seeds lost from the experimental site from germinating.

\section{Experimental Design}

Our experimental design focussed on seed dispersal by the slipstream of a car. Therefore experiments were performed during dry and still weather conditions to exclude dispersal by wateraided adhesion or by ambient wind alone. To quantify the effect of multiple dispersal events caused by a sequence of passing vehicles, a medium sized estate car (Vauxhall Astra) was driven repeatedly along a road section where marked seeds were laid out.

We carried out this study on a tarmac surface parking area (coordinates: $50.68^{\circ}$ north, $2.26^{\circ}$ west) $120 \mathrm{~m}$ in length and $20 \mathrm{~m}$ in width, with a concrete kerb $7 \mathrm{~cm}$ in height, and bordered by a gravelled verge. The length of the parking area was divided into a $60 \mathrm{~m}$ acceleration zone, a $45 \mathrm{~m}$ distance over which seed dispersal was measured, and a final $15 \mathrm{~m}$ for deceleration and turning. The acceleration zone was used to achieve a speed of $48 \mathrm{~km} / \mathrm{h}$ (30 mph) which was kept constant through the seed dispersal zone. This equals the maximum speed allowed in urban areas throughout many European countries.

Longitudinal dispersal was measured using intervals marked perpendicularly across the traffic lane (Fig. 1). The first $2 \mathrm{~m}$ were marked at $0.5 \mathrm{~m}$ intervals, metres $2-10$, as well as one meter before starting line were marked at $1 \mathrm{~m}$ intervals, and metres 10 45 were marked at $5 \mathrm{~m}$ intervals. We also divided the lane into five sections parallel to the direction of car movement to track lateral movement of seeds (Fig. 1).

\section{Study species and tracking seeds}

We used four species known to be common along roads or whose spread has been linked to vehicle movement (Table 1): Ailanthus altissima (Mill.) Swingle, Ambrosia artemisïfolia L., Brassica napus L., Clematis vitalba $\mathrm{L}$.. In the following we will refer to these species by their genus name. These species are invasive at least in parts of Europe and are assumed to affect biodiversity and/or human health. The species were also selected to represent different seed morphologies (with and without appendices for wind dispersal, Fig. 2) to allow the influence of seed traits on dispersal by vehicles to be assessed.

All seeds were coloured with a fluorescent paint to allow them to be tracked during sequential dispersal events. To minimise weight gain of the seeds, we used fluorescent airbrush colours, applied with a spraying gun of $0.3 \mathrm{~mm}$ needle size (see [32] for details). To test the influence of colour application on wind-dispersal ability, the falling velocities of fifteen seeds of each species before and after colour application were measured using the equipment and method described in Askew et al. [33]. Paint application had a significant but small effect on falling velocity (Table 1). Falling velocity increased on average by $0.9 \%$ in Brassica and $1.3 \%$ in Ambrosia. Higher increases were observed for Clematis (7.1\%) and Ailanthus $(12.0 \%)$. This increase in falling velocities due to seed weight gain probably reduced dispersal distances, making our estimates somewhat conservative.

\section{Dispersal experiments}

In a first experiment, we placed 300 seeds each of Ambrosia and Brassica and 200 seeds each of Ailanthus and Clematis at the start line $(0 \mathrm{~m})$ of the $45 \mathrm{~m}$ dispersal zone. Seeds were spread evenly across the driving lane over a narrow strip extending $30 \mathrm{~cm}$ in front of the starting line.

The car was then driven repeatedly along the driving lane in a sequence of up to 80 "passes" in one direction. The car left the parking area to return to the starting point to avoid disturbing the seeds. Five sequences with different numbers of passes were tested - 1, 10, 20, 40 or 80 - with the lower numbers serving as the basis for the next sequence (i.e., to reach 10 passes, we recorded the seed distribution after 1 pass and then did another 9 passes). Each set of sequences was replicated 10 times on different days.

At the end of each sequence $(1 ; 10 ; 20 ; 40 ; 80)$, seed distribution over the grid formed by the perpendicular and parallel sections (see Fig. 1) was recorded. We searched for and located seeds using a strong LED-UV lamp [32] and so the experiment was performed at dusk, night and dawn. If any seed movement by the ambient wind was observed during seed searching, the trial was terminated and the data for this entire replicate discarded. We visually checked the car but never found any attached seeds. To get a better understanding of the trajectories of seeds in the airflow of the car, we filmed the first pass of the vehicle several times with a digital video camera at 30 frames/s.

In a second experiment we focussed on the lateral movement of the seeds using only two species of different seed morphology. Seeds of Ailanthus and Brassica were coloured with five different colours; each colour group of seeds was laid out in a different parallel road section (Fig. 1). At the $0 \mathrm{~m}$ line we placed 50 seeds in the driving lane and 25 in each of the other sections for Ailanthus, and 100 and 50 seeds respectively for Brassica. After a single pass, the positions of all seeds in the parallel and perpendicular sections were recorded and the seeds were collected. Any possibly remaining seeds were removed by cleaning the road with a professional vacuum cleaner. This procedure was replicated 50 times for each species.

\section{Data analysis}

To standardise the frequencies across the differently sized perpendicular sections, we divided the frequencies of the $5 \mathrm{~m}$ sections by 5 and multiplied those of the $0.5 \mathrm{~m}$ sections by 2; i.e. all frequencies were standardised in terms of the $1 \mathrm{~m}$ sections. We 


\section{Road sections:}

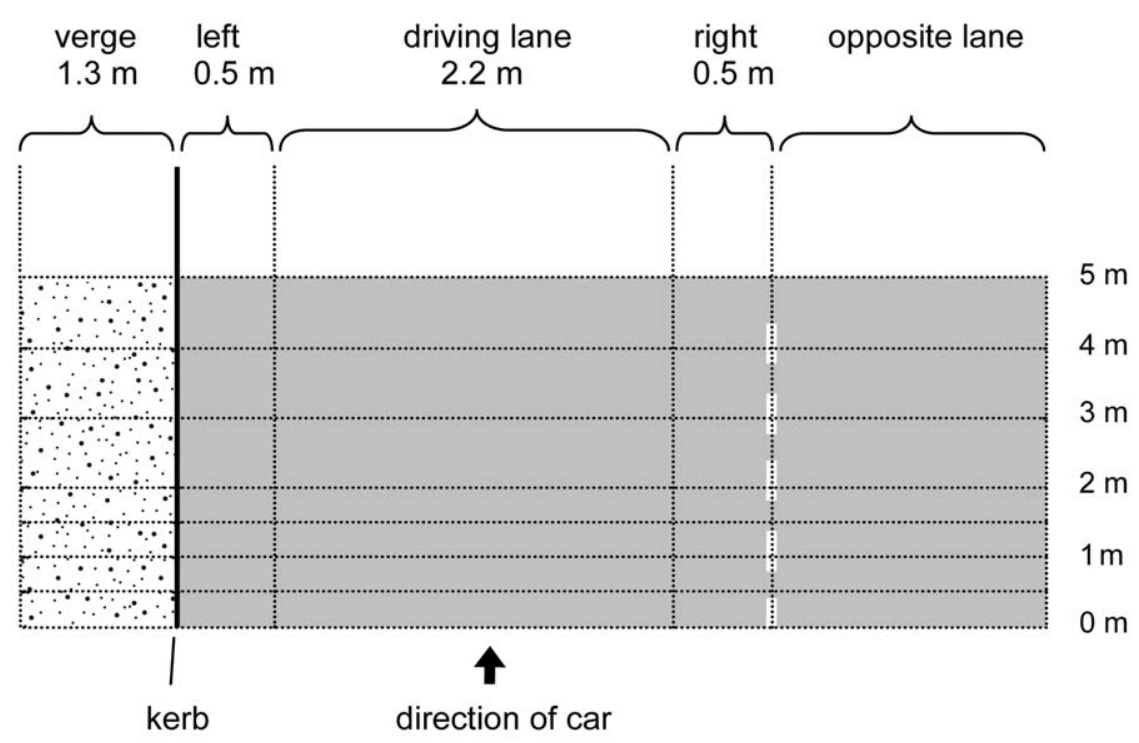

Figure 1. Sections of the study road. The car remained within the driving lane, making this the section most directly impacted by the passing vehicle. The adjoining sections (left and right) were not driven over, but would have been strongly affected by the vehicle's airflow. Seed settlement is considered to occur in the verge, which provides the most immediate establishment opportunity for seeds. The opposite lane represents the area beyond the midpoint of the lane, where, on a real road, the seed would be in the path of oncoming traffic. doi:10.1371/journal.pone.0052733.g001

fitted empirical dispersal models to the probability distributions of seeds along the road transect. Distance was represented as the longitudinal distance between the starting line and the end of each section. We chose three functions that are frequently used to model wind dispersal of seeds [34,35]: the Weibull, the Lognormal and the inverse Gaussian (Wald) functions. These functions were fitted to the probability data by generalised non-linear regression using the Proc NLMIXED function in SAS 9.2. This uses a maximum likelihood fitting procedure and is able to deal with non-normal errors; in this case a binomial distribution was used. The equations used were those supplied by Jongejans et al. [35]:

1) Wald: $f(r)=\left(\frac{b}{2 \pi r^{3}}\right)^{1 / 2} \exp \left(\frac{-b[r-a]^{2}}{2 a^{2 r}}\right)$

2) Lognormal: $f(r)=\frac{1}{b r(2 \pi)^{1 / 2}} \exp \left(\frac{-[\log r-a]^{2}}{2 b^{2}}\right)$

3) Weibull: $f(r)=a b r^{b-1} \exp \left(-a r^{b}\right)$

Table 1. Characteristics of the study species.
Where $f(r)$ is the probability that a seed is dispersed to a specific distance $r, a$ is the scale parameter and $b$ the shape parameter of the probability density functions (note that $a$ and $b$ have different values in each equation). We used Akaike's Information Criterion (AIC) to compare the fits of the different functions.

For the experiment on the lateral movement of seeds, we calculated the probability of reaching a certain section of the study road separately for the seed groups of each starting section. Probabilities were averaged over the 50 replicates and were displayed in a grid plot using the function 'image' (package 'graphics') of the statistical and programming environment R 2.10 [36].

Videos of the trajectories of seeds in the wake of the car were analysed by slow motion and single frame playback. We visually estimated the height of seed lift above the ground by relating it to the height of different parts of the vehicle.

\begin{tabular}{|c|c|c|c|}
\hline Species & Seed morphology & Falling velocity $(\mathrm{m} / \mathrm{s})$ & Association to transport corridors \\
\hline Ailanthus altissima & Winged & $0.84(0.75)$ & $\begin{array}{l}\text { Rapid range expansion along transport } \\
\text { corridors in the introduced range and } \\
\text { negative impacts on adjacent habitats }[50\end{array}$ \\
\hline Clematis vitalba & Plumed & $0.91(0.85)$ & $\begin{array}{l}\text { Rapid range expansion along transport } \\
\text { corridors in native and introduced range, } \\
\text { negative impacts on native forests [51] }\end{array}$ \\
\hline Brassica napus & Smooth & $3.8(3.8)$ & $\begin{array}{l}\text { Spread along roads, risk of escape of } \\
\text { genetically modified lineages }[46,48]\end{array}$ \\
\hline Ambrosia artemisiifolia & Hooked & $3.7(3.7)$ & $\begin{array}{l}\text { Severe allergenicity to humans, rapidly } \\
\text { spreading along roads in Europe [45] }\end{array}$ \\
\hline
\end{tabular}

Seed morphology, mean falling velocity of painted seeds (10 replicates, in brackets: unpainted seeds) and association to transport corridors of the four study species. doi:10.1371/journal.pone.0052733.t001 

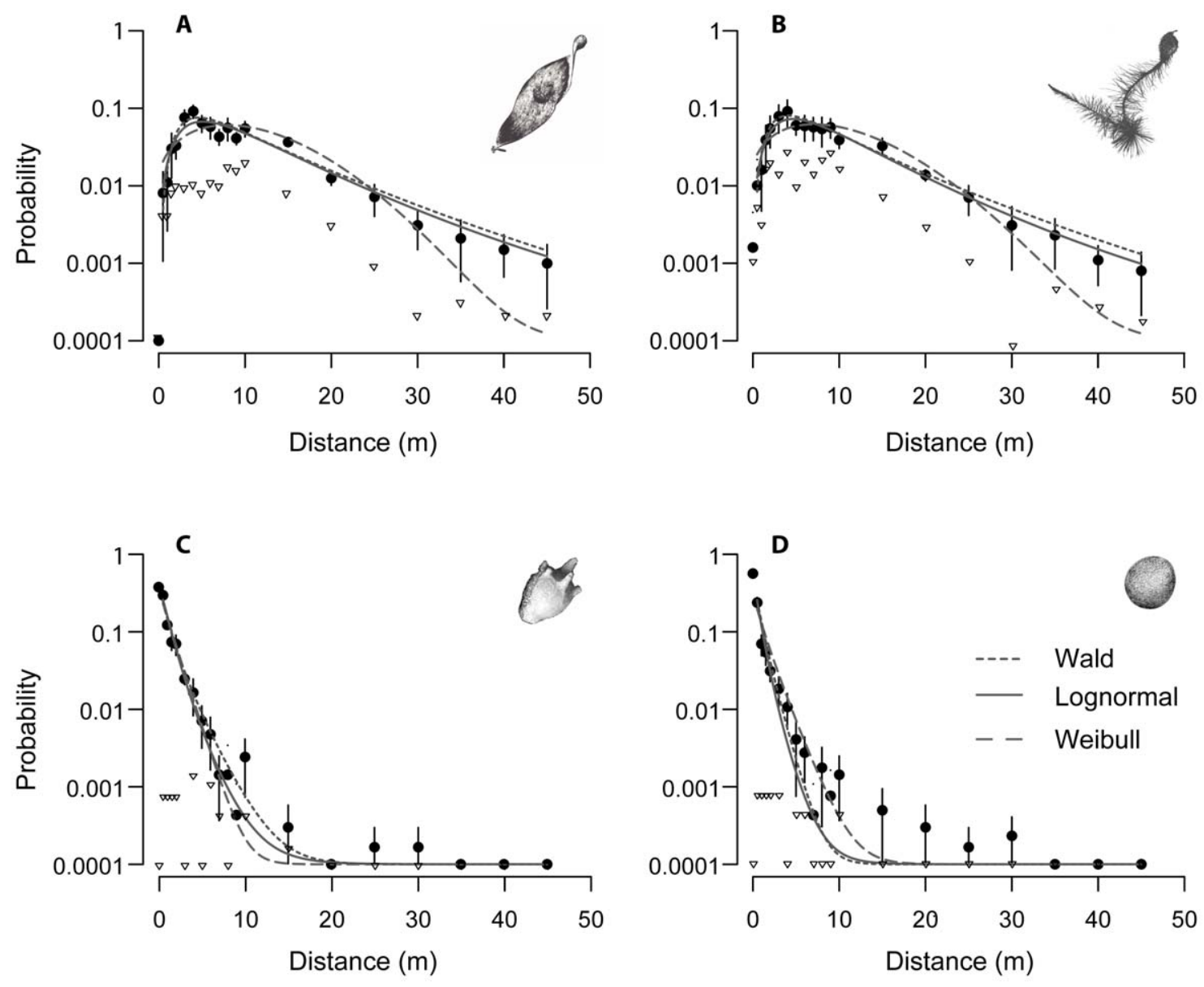

Figure 2. Probability distributions of seeds along the study road after $\mathbf{8 0}$ vehicle passes. (A) Ailanthus altissima (B) Clematis vitalba, (C) Ambrosia artemisiifolia and (D) Brassica napus. Filled circles represent the mean ( $\pm 95 \% \mathrm{Cl})$ probabilities of 10 replicates. The grey lines show the fitted dispersal functions. Open triangles show mean probabilities for seeds to reach the road verge at that distance along the line of travel. The $y$-axis is on a log scale and 0.0001 was added to all probabilities to show zero values. Note that this is not a total dispersal kernel but solely shows secondary dispersal by car's airflow.

doi:10.1371/journal.pone.0052733.g002

\section{Results}

\section{Dispersal distances and kernels}

Mean recapture rates $( \pm 1 \mathrm{SD})$ of viable diaspores after one vehicle pass were $94.5 \%( \pm 4.9)$ for Ailanthus, $93.2 \%( \pm 3.2)$ for Clematis, $93.8( \pm 1.4)$ for Brassica and 90.6\% ( \pm 4.4$)$ for Ambrosia. Losses were mainly due to seeds being crushed by tyres. Recapture rates decreased with increasing numbers of vehicle passes to $84.5 \%$ ( \pm 6.7$)$ for Ailanthus, $84.6 \%$ ( \pm 11.4 ) for Clematis, $80.7 \%( \pm 6.8)$ for Brassica and $72.0 \%$ ( \pm 5.8$)$ for Ambrosia after 80 rounds.

As the number of car passes increased, mean, median and $99 \%$ percentile of the dispersal distance of recaptured seeds increased but the relative effect diminished (Table 2). Probability distributions and mean dispersal distances were markedly similar for Ailanthus and Clematis, and for Brassica and Ambrosia (Figs. 2, 3; Table 2). The probability distributions of both Ailanthus and Clematis after 80 vehicle passes describe humped curves with the modes at approximately $5 \mathrm{~m}$ and a long tail extending over the entire $45 \mathrm{~m}$ section (Fig. 2a, b). As a measure of long distance dispersal, the $99 \%$ percentile of the probability distributions increased strongly from the first to ten passes in these species and remained constant at $40 \mathrm{~m}$ for 20 passes and more. In contrast, probability distributions for Brassica and Ambrosia after 80 passes peaked at the starting line $(0 \mathrm{~m})$ and then declined sharply up to a maximum distance of $30 \mathrm{~m}$ (Fig. 2c, d). We observed that both of these species were predominantly dispersed in the two narrow strips where the tyres passed. The $99 \%$ percentiles of both species reached $10 \mathrm{~m}$ (Ambrosia) and $15 \mathrm{~m}$ (Brassica) after 80 passes.

At the road verge, the seed densities for Ailanthus and Clematis after 80 passes followed a similarly shaped distribution as for all parallel sections combined, but were about an order of magnitude lower (Fig. 2). For Brassica and Ambrosia, dispersal to the road verge occurred only occasionally, and within the first $10 \mathrm{~m}$.

In the video analysis (see supporting information, Video S1), only trajectories of seeds of Ailanthus and Clematis were clearly visible. While the car was passing, a small proportion of the seeds were blown to both sides of the road. As soon as the car had completely passed the line of seeds, a strong linear movement of seeds in the driving direction was seen. Most seeds that were picked up by the slipstream were briefly lifted approximately $50 \mathrm{~cm}$ and then fell back to the ground, where they tumbled after the car.

Probability distributions were best fit by the Wald and the Lognormal function. This result was similar across all four species despite the very different seed distributions along the road. However, differences in AIC were generally low between all the dispersal functions tested. For Ailanthus and Clematis the Wald 
Table 2. Dispersal distances for the study species after different numbers of vehicle passes.

\begin{tabular}{|c|c|c|c|c|c|}
\hline \# vehicle passes & 1 & 10 & 20 & 40 & 80 \\
\hline \multicolumn{6}{|l|}{ Ailanthus altissima } \\
\hline Mean & $5.14 \pm 3.07$ & $9.85 \pm 7.97$ & $9.95 \pm 7.84$ & $10.33 \pm 7.96$ & $10.83 \pm 8.11$ \\
\hline Median & 5 & 8 & 8 & 8 & 8 \\
\hline $99^{\text {th }}$ percentile & 15 & 40 & 40 & 40 & 40 \\
\hline \multicolumn{6}{|l|}{ Clematis vitalba } \\
\hline Mean & $4.95 \pm 3.43$ & $9.19 \pm 7.52$ & $9.94 \pm 7.93$ & $10.08 \pm 8.03$ & $10.46 \pm 8.00$ \\
\hline Median & 4 & 7 & 8 & 8 & 8 \\
\hline $99^{\text {th }}$ percentile & 15 & 35 & 40 & 40 & 40 \\
\hline \multicolumn{6}{|l|}{ Brassica napus } \\
\hline Mean & $0.98 \pm 1.12$ & $1.26 \pm 1.88$ & $1.60 \pm 2.62$ & $1.59 \pm 2.66$ & $1.71 \pm 2.87$ \\
\hline Median & 0.5 & 0.5 & 0.5 & 0.5 & 1 \\
\hline $99^{\text {th }}$ percentile & 4 & 8 & 12 & 10 & 15 \\
\hline \multicolumn{6}{|c|}{ Ambrosia artemisiifolia } \\
\hline Mean & $1.04 \pm 1.07$ & $1.38 \pm 1.85$ & $1.51 \pm 1.92$ & $1.64 \pm 2.03$ & $1.59 \pm 2.05$ \\
\hline Median & 0.5 & 0.5 & 1 & 1 & 1 \\
\hline $99^{\text {th }}$ percentile & 5 & 9 & 9 & 9 & 10 \\
\hline
\end{tabular}

Note our recapture rates given under 'results'. Also note that movement along the road decreased considerably for multiple vehicle passes but resulted in increased lateral transport. Dispersal distances might change greatly when dispersal by car's airflow interacts with other forms of dispersal (e.g. wind) transporting seeds back to the driving lane.

doi:10.1371/journal.pone.0052733.t002

function resulted in a marginally lower AIC, whereas the Lognormal function better described the dispersal tails (Fig. 2). The Wald function slightly overestimated the tails of the kernels while the Weibull clearly underestimated them, despite having a relatively low AIC. Estimated shape parameters for all functions were very similar for Ailanthus and Clematis (Table 3). For Ambrosia and Brassica, Lognormal functions fitted dispersal kernels only at a slightly smaller AIC than the Wald function. All functions predict very low probabilities for both species to disperse more than $20 \mathrm{~m}$. (For more details see supporting information, Table S1)

The shape of the dispersal kernels changed with increasing vehicle passes. At higher numbers of passes, the fitted kernels for Ailanthus and Clematis show similar modes, but a fatter tail (Fig. 3). For Ambrosia and Brassica the decline in the dispersal kernels was less steep at higher numbers of passes and reached a probability of zero at a distance approximately $5 \mathrm{~m}$ further from the starting point compared to the first vehicle pass. The change in the shape of the dispersal kernel for all species was most pronounced between 1 and 20 rounds while the changes between 20 and 80 rounds were less pronounced.

\section{Lateral movement of seeds}

In the first experiment, we observed considerable lateral transport of seeds to the verge in Ailanthus and Clematis, but not in the other species (Fig. 2 a, b). There was a rapid accumulation of seeds at both sides of the driving lane (Fig. 4). After 10 vehicle passes, only a small proportion $(<4 \%)$ of Ailanthus seeds remained in the driving lane (Fig. 4a; similar results were found for Clematis and are not shown). Seeds accumulated rapidly in the opposite lane, in the left lane along the kerb, and in the road verge, but the right lane showed negligible accumulation. Accumulation of seeds in the road verge increased asymptotically with the number of vehicle passes, reaching a plateau of about $20 \%$ of seeds after 40 passes (Fig. 4b).
The second experiment clarified the lateral transport of seeds of Ailanthus that were laid out at different starting sections of the study road (Fig. 5). Seeds placed at the road verge moved only slightly, whereas the seeds placed in the driving lane were transported farthest across the road and reached all other parallel sections with high probabilities. Seeds put into the left or right section adjoining the driving lane travelled only to the immediately neighbouring sections and were transported over much shorter distances.

In contrast to Ailanthus and Clematis, seeds of Brassica and Ambrosia largely remained in the driving lane (Fig. 2). Even after 80 rounds of vehicle passes, fewer than $10 \%$ of seeds of either species were transported to the side lanes and only a negligible proportion $(<1 \%)$ reached the road verge or the opposite lane (Fig. 2c, d). The second experiment confirmed very low lateral transport for seeds of Brassica.

\section{Discussion}

Previous research has revealed that vehicles serve as agents of long-distance dispersal either in terms of long-lasting attachment of seeds $[10,13,15]$ or through spillage during transport of goods $[37,38]$. Our results add the mechanism of repeated stepwise dispersal of seeds over road surfaces by the airflow of passing vehicles. Dispersal by airflow may interact with other dispersal vectors, traffic related as well as wind [39] and animals, which has considerable implications for long distance dispersal. The high rates of recaptured seeds on the ground demonstrate that under dry weather conditions attachment of seeds to vehicles is low. Our video analysis revealed that the majority of seeds from species with morphological adaptations to wind dispersal were indeed transported with the slipstream of the passing car.

\section{Dispersal distances}

The distances we observed for secondary dispersal by vehicle airflow are on a scale similar to the primary dispersal distances 

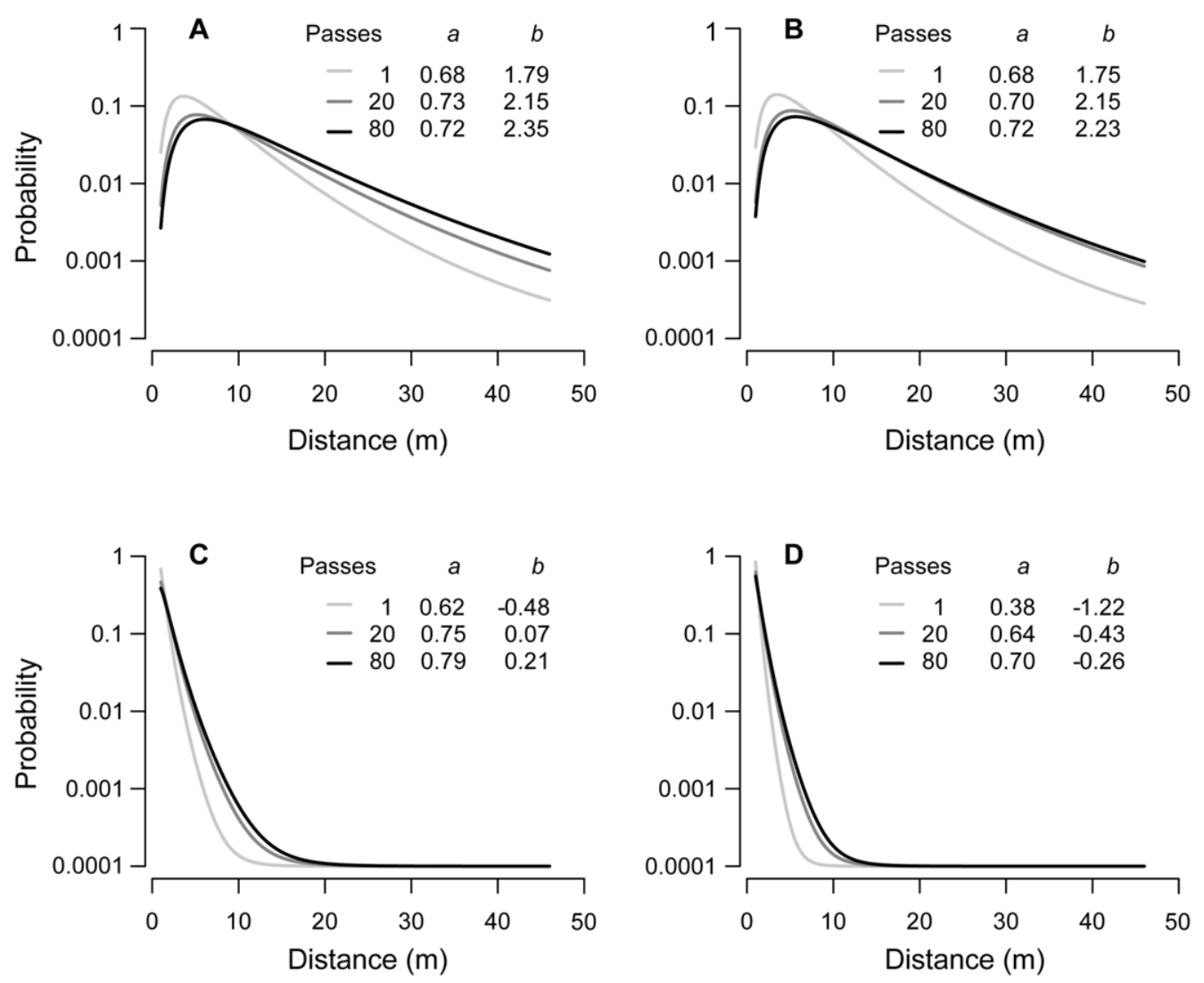

Figure 3. Effect of the number of vehicle passes on the shape of the fitted dispersal kernel (Lognormal function). (A) Ailanthus altissima, (B) Clematis vitalba, (C) Ambrosia artemisiifolia, and (D) Brassica napus. The $y$-axis is on a log scale and 0.0001 was added to all probabilities to show zero values. Inset tables show parameter estimates ( $a=$ scale parameter, $b=$ shape parameter) for the different numbers of vehicle passes. doi:10.1371/journal.pone.0052733.g003

Table 3. Parameter estimates and AIC for different dispersal functions.

\begin{tabular}{|c|c|c|c|c|}
\hline Species & Model & $a$ & $b$ & AIC \\
\hline \multicolumn{5}{|c|}{ Ailanthus altissima } \\
\hline & Weibull & 1.858 & 0.008 & 44.0 \\
\hline & Lognormal & 0.724 & 2.307 & 43.2 \\
\hline & Wald & 20.456 & 12.952 & 43.1 \\
\hline \multicolumn{5}{|c|}{ Clematis vitalba } \\
\hline & Weibull & 1.779 & 0.011 & 46.3 \\
\hline & Lognormal & 0.724 & 2.229 & 45.5 \\
\hline & Wald & 18.366 & 12.275 & 45.4 \\
\hline \multicolumn{5}{|c|}{ Brassica napus } \\
\hline & Weibull & 0.852 & 0.975 & 40.7 \\
\hline & Lognormal & 0.697 & -0.260 & 34.7 \\
\hline & Wald & 1.621 & 1.089 & 35.2 \\
\hline \multicolumn{5}{|c|}{ Ambrosia artemisiifolia } \\
\hline & Weibull & 0.976 & 0.847 & 39.9 \\
\hline & Lognormal & 0.791 & 0.211 & 39.6 \\
\hline & Wald & 1.270 & 1.357 & 39.7 \\
\hline
\end{tabular}

reported for our study species. Soons and Ozinga [40] modelled a median distance of $10.1 \mathrm{~m}$ and a $99^{\text {th }}$ percentile of $100 \mathrm{~m}$ for wind dispersal of Clematis. Matlack [41] observed a maximum distance of $112 \mathrm{~m}$ for wind dispersal of Ailanthus. Whereas the median distance is comparable, these values are approximately double those for secondary dispersal by a vehicle after 80 passes. Colbach et al. [42] found a mean primary dispersal distance of $0.5 \mathrm{~m}$ and a $99^{\text {th }}$ percentile of $1.6 \mathrm{~m}$ for Brassica, which amounts to approximately half to one tenth the respective values for secondary dispersal observed in this study. Our results give experimental evidence that distances of seed dispersal by car's airflow can be equal and even higher compared to natural dispersal.

Dispersal by means of seeds attaching to the surface of vehicles is affected by seed size and seed mass [10,13]. In this study, falling velocity triggered by morphological adaptations for wind dispersal appeared to be important. Species with plumes (Clematis) or wings (Ailanthus) were moved over much greater mean distances than species without such adaptations (Table 1). Figure 2 demonstrates strikingly congruent dispersal kernels for the species with wind dispersal morphologies, and also for the two species without such morphologies. This coincides with similar falling velocities of Ailanthus and Clematis, and of Brassica and Ambrosia, respectively suggesting that falling velocity influences secondary dispersal by vehicle airflow as it does for primary wind dispersal [33].

For Brassica and Ambrosia our observation of a higher degree of seed movement in the areas traversed by tyres might suggest short contact with tyres rather than airflow accounts for dispersal. Although we cannot separate the effect of tyre contact and airflow 

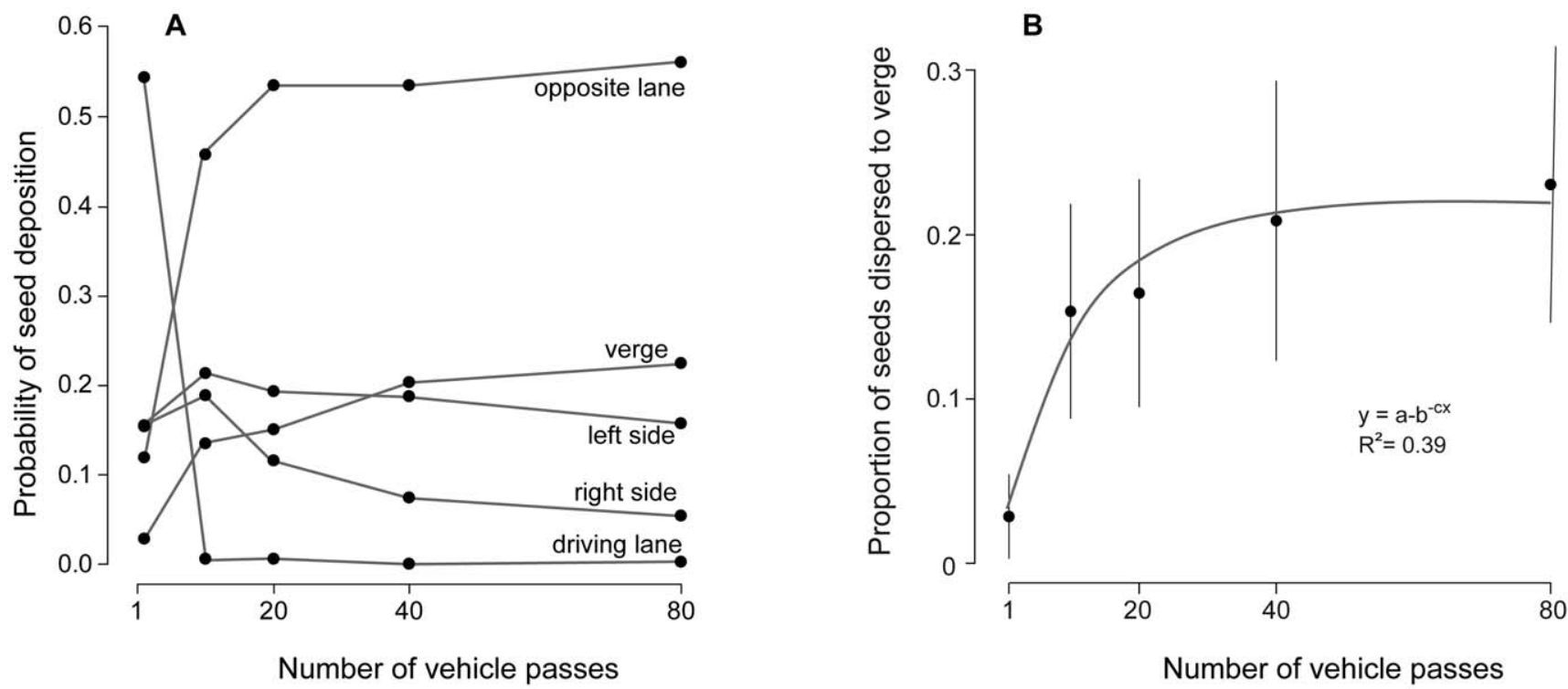

Figure 4. Lateral movement of seeds of Ailanthus altissima in relation to the number of vehicle passes. (A) Mean probabilities of seed deposition of Ailanthus altissima in the parallel road sections in relation to the number of vehicle passes. (B) Proportion ( $\pm 95 \% \mathrm{Cl})$ of seeds of Ailanthus altissima accumulating at the verge in relation to the number of vehicle passes. At the start of experiment seeds were laid out only on the driving lane.

doi:10.1371/journal.pone.0052733.g004

in this experiment, the different shapes of the dispersal kernels for Ailanthus and Clematis versus Brassica and Ambrosia suggest different processes with the former two species being more influenced by the airflow.

\section{Airflow dispersal of species with morphological adaptation to wind dispersal}

For Ailanthus and Clematis the shape of the dispersal kernel and the strong lateral movement of seeds even from sections adjoining the driving lane indicate a dominant effect of vehicle airflow on the dispersal process. Solazzo et al. [20] found a sizeable effect of vehicle airflow on the distribution of particulate matter along roads, primarily caused by the slipstream of passing cars. Likewise, the slipstream of the car appeared to move the seeds in our experiment almost exclusively in the direction of traffic. As a second process, sideward eddies near the ground [18] and sideways components of the airflow [19] are likely to cause a simultaneous strong lateral dispersal to each side of the driving lane. This lateral movement takes seeds away from the influence of subsequent vehicles. Although this process greatly decreases

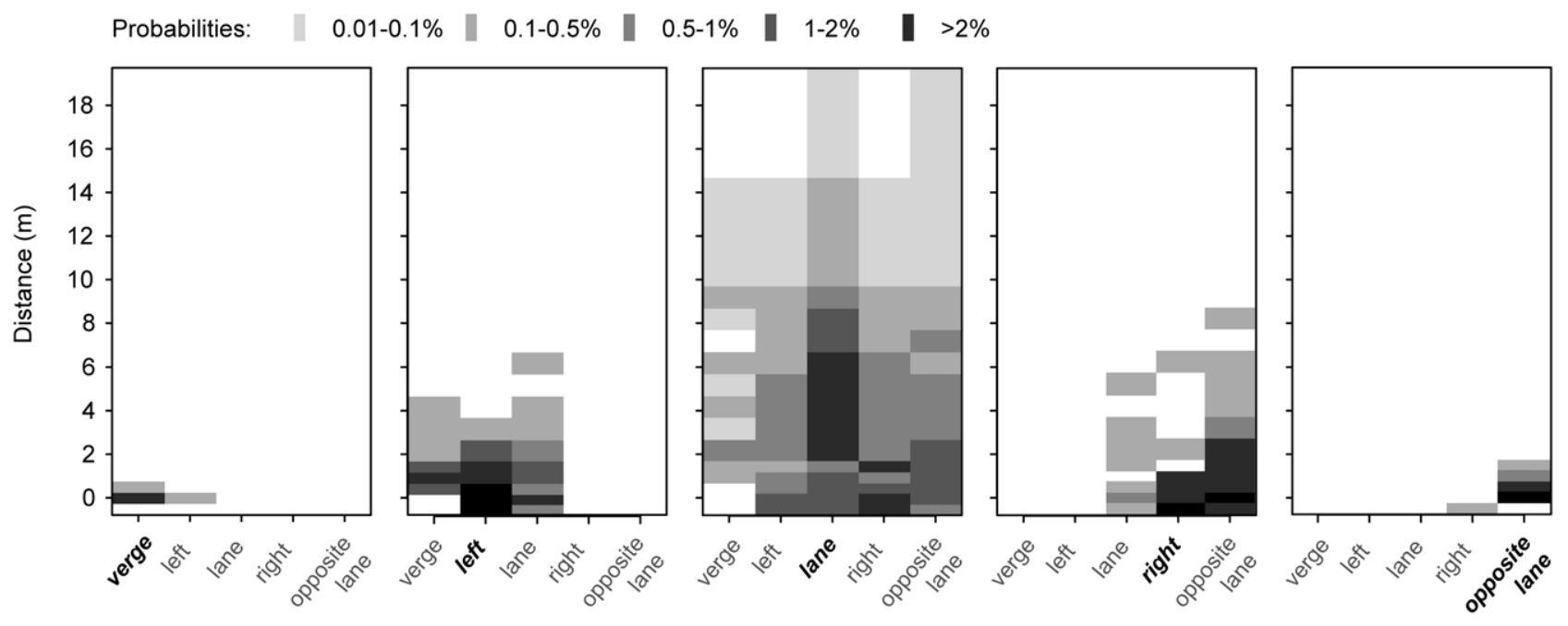

Road section

Figure 5. Influence of the starting section on parallel and lateral movement of seeds by a passing car. Dispersal patterns of Ailanthus altissima seeds after one vehicle pass for seeds initially placed in the verge (left panel), the left side (second panel from left) the driving lane (centre panel), the right side (second panel from right) and the opposite lane (right panel). Probabilities of reaching the different sections of the study road are indicated by different grey shading. Probabilities are averaged over 50 replicates.

doi:10.1371/journal.pone.0052733.g005 
longitudinal dispersal distances, it effectively transports seeds from the road surface to potentially suitable establishment sites at the road verge. This suggests a strong effect of vehicle airflow on realised dispersal, i.e. the proportion of dispersed seeds that can germinate and establish successfully. However, secondary dispersal by ambient wind [39] may move some seeds back onto the road where they are available for further dispersal by airflow, again.

The mechanisms behind the strong lateral movement are partially revealed by our additional experiment for Ailanthus. Seeds placed in the driving lane showed a wide lateral dispersion after the vehicle passed, while seeds placed in the adjoining sections showed shorter transport distances and lower overall probabilities of lateral transport (Fig. 4, 5). Repeated passes by vehicles will therefore result in a higher lateral transport from the driving lane to adjoining sections rather than towards the driving lane. This is in accordance with the low lateral reach of the slipstream effect in the wake of a moving vehicle in contrast with the significant airflow behind, which extends over a distance of 40 times the vehicle height [19]. While most commonly seeds might be starting at the road verge they are least likely to travel long distance by car's airflow. Conversely the highest probabilities of long distance dispersal have those seeds exposed on the driving lane. Yet, the number of these seeds strongly depends on primary and secondary dispersal by other vectors.

A mechanistic model for wind dispersal over the ground has been introduced and successfully validated with experimental data [25]. This model describes dispersal distances over a given time span as a function of wind drag and friction of the surface that a seed is experiencing. The airflow caused by passing vehicles has also been successfully modelled by computational fluid dynamics [20]. Thus, if the horizontal wind vector of a vehicle in motion and the friction of the road surface are analysed, a fully mechanistic description of vehicle dispersal might be obtained. However, as indicated by the video analysis (see supporting information, Video $\mathrm{S} 1$ ), tumble dispersal over the ground is only part of the process for wind dispersed species. Another is in-air wind dispersal once the seeds have been lifted by the turbulence caused by the passing car. Turbulence and updrafts caused by ambient wind have been shown to be important in long-distance primary dispersal by wind $[22,24,43,44]$. Updrafts are probably caused by the turbulences close to the passing car where several upward and sideward eddies occur [18]. Seeds elevated by turbulence are subjected to the slipstream of the vehicle which may greatly extend dispersal distances compared to tumble dispersal. In addition, this process could interact with dispersal over sealed surfaces of transport corridors by the ambient wind [39].

\section{Airflow dispersal of species without adaptation to wind dispersal}

Our results expand upon previous experiments on vehicle-aided dispersal of Brassica and Ambrosia. Both species have seeds without obvious morphological adaptations to enhance wind dispersal and accordingly our study found low dispersal distances. Limited dispersal with a maximum distance of $21.5 \mathrm{~m}$ was also found for seeds of Brassica that were placed on a rural road [17]. Seed transport of Ambrosia by vehicles from dense roadside populations resulted in a low density seed rain within the first $25 \mathrm{~m}$ of the seed trap transect [45]. Still both species have spread conspicuously along roads $[46,47]$ and several studies found a strong association of roadside populations of Brassica with the direction of traffic flow, e.g. in the direction of processing plants [37,47,48]. Hence, dispersal mechanisms other than the slipstream of vehicles appear to enhance long-distance dispersal in these species. In previous experiments we found that spillage of Brassica seeds during crop transport [38], might explain distributional patterns at the landscape scale. Also, transport of seeds by mowing vehicles has been shown to be an effective means of Ambrosia dispersal along road corridors [45].

\section{Generality of the experimental results}

As the secondary dispersal distances observed in this experiment are on a comparable scale to the primary dispersal distances of our species, secondary HMD by vehicles enhances the spread of these species with a special focus along road corridors. The combination of different processes under field conditions could further increase dispersal distances. Seeds transported by attachment to vehicles could - after detachment - be picked up by the airflow of subsequent vehicles. By causing lateral transport towards suitable germination sites at the road verge, the airflow of vehicles could allow such long distance dispersal to end successfully. Furthermore, other processes such as wind related dispersal [25,39] or lateral dispersal by vehicles in the opposite driving lane (Fig. 5) could bring seeds back on the driving lane and under the influence of vehicle airflow which would allow repeated dispersal events in the same direction. As speed, mass and shape of vehicles influence their airflow [18], we would expect the effect of vehicles travelling on motorways to be much greater than recorded here. However, seed mortality due to crushing by tyres might also be enhanced by higher volumes of traffic. For a vector-specific analysis of dispersal, these losses could be looked at as the cost of this dispersal process [49].

The observations at our study road were limited to a longitudinal distance of $45 \mathrm{~m}$ (and no seeds were found in the turning zone beyond $45 \mathrm{~m}$ ). While the mode of the dispersal kernel and its decline to this distance could be reliably estimated, the scale of the experiment did not allow for the detection of dispersal events that reach beyond this distance. Further distances could be expected for the wind-dispersed species as most replicates in our experiment recorded seeds in the farthest sections.

In our experiment we used only one car and therefore the time between passes was rather long ( $>1$ minute). In reality traffic is often dense, time intervals are shorter and seeds, especially those with low falling velocities, could be kept in the air for a long time by the flow of traffic. Therefore our experiment could underestimate the dispersal distances compared to the same number of passes by consecutive vehicles.

Finally, the weather conditions may affect the relative importance of different dispersal processes. In our experiment, which was always conducted under dry conditions, a large proportion of the seeds of Brassica and Ambrosia remained in the lane even after 80 passes. It remains unclear whether such low lateral transport under wet conditions may offer an advantage for long-distance dispersal via attachment to car's surface.

\section{Conclusions}

Human-mediated dispersal has often been characterized as a highly stochastic process that is difficult to quantify, but that has a large effect on long-distance dispersal. Our study contributes to a better understanding of one HMD process, both quantitatively and mechanistically.

Dispersal processes along roads, both anthropogenic and natural, are manifold and include long and short term attachment to car (body versus tyres), vehicle airflow along roads as well as lateral transport, wind dispersal (airborne and sealed surfaces) and tumble dispersal. All these dispersal mechanisms may result in complex interactions considerably enhancing dispersal distances. A better understanding of these interacting dispersal processes may help to increase the accuracy of models of 
range expansion of invasive species. The high volume of traffic (more than 25 million cars on British roads by 1997 [10]) illustrates the quantitative relevance and potential impact of this dispersal vector within urban areas and beyond. Therefore, HMD in general $[1,3,14,15]$ and vehicle airflow in particular play an important role in understanding and managing invasive species in particular and in conservation ecology in more general. For example, our results on the strong lateral movement of seeds in the slipstream of passing cars might stimulate a changed design of road edges that then hampers lateral movement of seeds from road surface to verge.

\section{Supporting Information}

Video S1 Video of the study car moving along the study road. The car was filmed after new seeds of all species were laid out in front of the zero line. The markings indicating the sections

\section{References}

1. Wichmann MC, Alexander MJ, Soons MB, Galsworthy S, Dunne L, et al. (2009) Human-mediated dispersal of seeds over long distances. Proc R Soc London B-Biol Sci 276: 523-532.

2. Pickering CM, Mount A, Wichmann MC, Bullock JM (2011) Estimating human-mediated dispersal of seeds within an Australian protected area. Biol Invasions 13: 1869-1880.

3. Wilson JRU, Dormontt EE, Prentis PJ, Lowe AJ, Richardson DM (2009) Something in the way you move: dispersal pathways affect invasion success. Trends Ecol Evol 24: 136-144.

4. Wilcox DA (1989) Migration and control of purple loosestrife (Lythrum salicaria L.) along highway corridors. Environ Manag 13: 365-370.

5. Lavoie C, Jodoin Y, de Merlis AG (2007) How did common ragweed (Ambrosia artemisiifolia L.) spread in Quebec? A historical analysis using herbarium records. J Biogeogr 34: 1751-1761.

6. Vilà M, Pujadas J (2001) Land-use and socio-economic correlates of plant invasions in European and North African countries. Biol Conserv 100: 397-401.

7. Dark SJ (2004) The biogeography of invasive alien plants in California: an application of GIS and spatial regression analysis. Divers Distrib 10: 1-9.

8. Niggemann M, Jetzkowitz J, Brunzel S, Wichmann MC, Bialozyt R (2009) Distribution patterns of plants explained by human movement behaviour. Ecol Model 220: 1339-1346.

9. Clifford HT (1959) Seed dispersal by motor vehicles. J Ecol 47: 311-315.

10. Hodkinson DJ, Thompson K (1997) Plant dispersal: The role of man. J Appl Ecol 34: 1484-1496.

11. Lonsdale WM, Lane AM (1994) Tourist vehicles as vectors of weed seeds in Kakadu National Park, Northern Australia. Biol Conserv 69: 277-283.

12. Schmidt W (1989) Plant dispersal by motor cars. Vegetatio 70: 147-152.

13. Zwaenepoel A, Roovers P, Hermy M (2006) Motor vehicles as vectors of plant species from road verges in a suburban environment. Basic Appl Ecol 7: 83-95.

14. Taylor K, Brummer T, Taper ML, Wing A, Rew LJ (2012) Human-mediated long-distance dispersal: an empirical evaluation of seed dispersal by vehicles. Divers Distrib 18: 942-951.

15. von der Lippe M, Kowarik I (2007) Long-distance dispersal of plants by vehicles as a driver of plant invasions. Conserv Biol 21: 986-996.

16. von der Lippe M, Kowarik I (2008) Do cities export biodiversity? Traffic as dispersal vector across urban-rural gradients. Divers Distrib 14: 18-25.

17. Garnier A, Pivard S, Lecomte J (2008) Measuring and modelling anthropogenic secondary seed dispersal along roadverges for feral oilseed rape. Basic Appl Ecol 9: 533-541.

18. Hucho W-H, editor (2003) Aerodynamics of road vehicles. From fluid mechanics to vehicle engineering. 4th ed. Warrendale: SAE International. $938 \mathrm{p}$.

19. Eskridge RE, Hunt JCR (1979) Highway modeling. 1. Prediction of velocity and turbulence fields in the wake of vehicles. J Appl Meteorol 18: 387-400.

20. Solazzo E, Cai XM, Vardoulakis S (2008) Modelling wind flow and vehicleinduced turbulence in urban streets. Atmos Environ 42: 4918-4931.

21. Soons MB, Bullock JM (2008) Non-random seed abscission, long-distance wind dispersal and plant migration rates. J Ecol 96: 581-590.

22. Nathan R, Katul GG, Horn HS, Thomas SM, Oren R, et al. (2002) Mechanisms of long-distance dispersal of seeds by wind. Nature 418: 409-413.

23. Tackenberg $\mathrm{O}$ (2003) Modeling long-distance dispersal of plant diaspores by wind. Ecol Monogr 73: 173-189.

24. Soons MB, Heil GW, Nathan R, Katul GG (2004) Determinants of longdistance seed dispersal by wind in grasslands. Ecology 85: 3056-3068.

25. Schurr FM, Bond WJ, Midgley GF, Higgins SI (2005) A mechanistic model for secondary seed dispersal by wind and its experimental validation. J Ecol 93: 1017-1028.

26. Bullock JM, Clarke RT (2000) Long distance seed dispersal by wind: measuring and modelling the tail of the curve. Oecologia 124: 506-521. parallel and perpendicular to the direction of traffic (Fig. 1) are visible.

(AVI)

Table S1 Parameter estimates and AIC of the Lognormal and Wald function for dispersal at three different numbers of vehicles passes.

(DOC)

\section{Acknowledgments}

Our thanks are due to K. Thompson who measured falling velocity of seeds and C. Pfeifer for his help with non-linear regression.

\section{Author Contributions}

Conceived and designed the experiments: ML MW JMB. Performed the experiments: ML TK MW. Analyzed the data: ML MW JMB. Wrote the paper: ML MW JMB IK.

27. Römermann C, Tackenberg O, Poschlod P (2005) How to predict attachment potential of seeds to sheep and cattle coat from simple morphological seed traits. Oikos 110: 219-230.

28. Morales JM, Carlo TSA (2006) The effects of plant distribution and frugivore density on the scale and shape of dispersal kernels. Ecology 87: 1489-1496.

29. Russo SE, Portnoy S, Augspurger CK (2006) Incorporating animal behavior into seed dispersal models: Implications for seed shadows. Ecology 87: 3160-3174

30. Bullock JM, Galsworthy SJ, Manzano P, Poschlod P, Eichberg C, et al. (2011) Process-based functions for seed retention on animals: a test of improved descriptions of dispersal using multiple data sets. Oikos 120: 1201-1208.

31. Myers JA, Vellend M, Gardescu S, Marks PL (2004) Seed dispersal by whitetailed deer: implications for long-distance dispersal, invasion, and migration of plants in eastern North America. Oecologia 139: 35-44.

32. Lemke A, von der Lippe M, Kowarik I (2009) New opportunities for an old method: using fluorescent colours to measure seed dispersal. J Appl Ecol 46: 1122-1128.

33. Askew AP, Corker D, Hodkinson DJ, Thompson K (1997) A new apparatus to measure the rate of fall of seeds. Funct Ecol 11: 121-125.

34. Greene DF, Canham CD, Coates KD, Lepage PT (2004) An evaluation of alternative dispersal functions for trees. J Ecol 92: 758-766.

35. Jongejans E, Skarpaas O, Shea K (2008) Dispersal, demography and spatial population models for conservation and control management. Perspect Plant Ecol Evol Syst 9: 153-170.

36. R Development Core Team (2009) R: A language and environment for statistical computing. Vienna: R Foundation for Statistical Computing. URL http://www.R-project.org. ISBN 3-900051-07-0.

37. Crawley MJ, Brown SL (2004) Spatially structured population dynamics in feral oilseed rape. Proc R Soc London B-Biol Sci 271: 1909-1916.

38. von der Lippe M, Kowarik I (2007) Crop seed spillage along roads: a factor of uncertainty in the containment of GMO. Ecography 30: 483-490.

39. Kowarik I, von der Lippe M (2011) Secondary wind dispersal enhances longdistance dispersal of an invasive species in urban road corridors. NeoBiota 9: 4970 .

40. Soons MB, Ozinga WA (2005) How important is long-distance seed dispersal for the regional survival of plant species? Divers Distrib 11: 165-172.

41. Matlack GR (1987) Diaspore size, shape, and fall behavior in wind-dispersed plant species. Am J Bot 74: 1150-1160.

42. Colbach N, Clermont-Dauphin C, Meynard JM (2001) GENESYS: a model of the influence of cropping system on gene escape from herbicide tolerant rapeseed crops to rape volunteers - II. Genetic exchanges among volunteer and cropped populations in a small region. Agric Ecosyst Environ 83: 255-270.

43. Katul GG, Porporato A, Nathan R, Siqueira M, Soons MB, et al. (2005) Mechanistic analytical models for long-distance seed dispersal by wind. Am Nat 166: $368-381$.

44. Tackenberg O, Poschlod P, Kahmen S (2003) Dandelion seed dispersal: The horizontal wind speed does not matter for long-distance dispersal - it is updraft! Plant Biology 5: 451-454.

45. Vitalos M, Karrer G (2009) Dispersal of Ambrosia artemisiifolia seeds along roads: the contribution of traffic and mowing machines. In: Pyšek P, Pergl J, editors. Biological invasions: Towards a synthesis. pp. 53-60.

46. Essl F, Dullinger S, Kleinbauer I (2009) Changes in the spatio-temporal patterns and habitat preferences of Ambrosia artemisiifolia during its invasion of Austria. Preslia 81: 119-133.

47. Knispel AL, McLachlan SM (2010) Landscape-scale distribution and persistence of genetically modified oilseed rape (Brassica napus) in Manitoba, Canada. Environ Sci Pollut Res Int 17: 13-25. 
48. Kawata M, Murakami K, Ishikawa T (2009) Dispersal and persistence of genetically modified oilseed rape around Japanese harbors. Environ Sci Pollut Res Int 16: 120-126.

49. Bonte D, Van Dyck H, Bullock JM, Coulon A, Delgado M, et al. (2012) Costs of dispersal. Biol Rev Camb Philos Soc 87: 290-312.
50. Kowarik I, Säumel I (2007) Biological flora of Central Europe: Ailanthus altissima (Mill.) Swingle. Perspect Plant Ecol Evol Syst 8: 207-237.

51. Ogle CC, Cock GDL, Arnold G, Mickleson N (2000) Impact of an exotic vine Clematis vitalba (F. Ranunculaceae) and of control measures on plant biodiversity in indigenous forest, Taihape, New Zealand. Austral Ecol 25: 539-551. 